\title{
Effects of Heat Treatment on Microhardness of Some Al-Cu Alloy Prepared by Vacuum Coating
}

\author{
Safdar Habibi ${ }^{*}$, Babak Jaleh1, Amir Namdarmanesh' ${ }^{2}$, Mojtaba Shamlo1 \\ ${ }^{1}$ Physics Department, Bu Ali Sina University, Hamedan, Iran \\ ${ }^{2}$ Physics Department, Payam Nour University, Tehran, Iran \\ Email: *safdar@basu.ac.ir
}

Received 16 March 2014; revised 29 April 2014; accepted 14 May 2014

Copyright (C) 2014 by authors and Scientific Research Publishing Inc.

This work is licensed under the Creative Commons Attribution International License (CC BY). http://creativecommons.org/licenses/by/4.0/

c) (i) Open Access

\begin{abstract}
In this paper binary alloy of $\mathrm{Al}-\mathrm{Cu}$ with composition $\mathrm{Al}_{(100-x)} \mathrm{Cu}_{\mathrm{x}},(\mathrm{x}=10,15,20)$ is prepared by thermal evaporation method. The prepared samples are annealed at different temperatures and investigated by XRD and microhardness method. XRD has been used to show amorphous state of structures and microhrdness tester show the increase in hardness due to the increase in amount of Al in the alloy. SEM and AFM were also used to show information about the surface of the specimen, resulting some densification and relaxation in these specimens.
\end{abstract}

\section{Keywords}

\section{Al Alloy, Amorphous Materials, Microhardness, Heat Treatment}

\section{Introduction}

$\mathrm{Al}$ and $\mathrm{Al}$ alloys are widely used in industry and technology such as aerospace industry because of their unique properties such as good corrosion resistance, light weight and high mechanical hardness [1]. However, despite their unique properties they are normally brittle. Ductility in this material can be improved by 1) addition of certain amounts of $\mathrm{Cu}$ and 2) by change in preparation method to avoid crystallization. Since grain boundaries and defects are the main reasons for brittleness in crystalline materials [2] [3]. On the other hand, ductility can be improved if the material is prepared in the form of amorphous structure. But amorphous phase usually is a meta-stable phase and needs some heat treatment to get more stability provided that the heat treatment is selected carefully [4] [5]. Thermal annealing of amorphous materials can generally make several changes in these

\footnotetext{
"Corresponding author.
} 
alloys. Bulk and surface crystallization, and nanocrystallisation can be imposed on these materials upon thermal annealing [6]-[8]. However low temperature thermal annealing can transfer these alloys to a more stable amorphous state through structural relaxation, enhancing their hardness, ductility and other properties and also increase in density [9]-[11]. In this paper, alloy of $\mathrm{Al}_{(100-x)} \mathrm{Cu}_{\mathrm{x}}$ with $\mathrm{x}=10,15,20$ is prepared by evaporation method. Then the prepared specimens were annealed at temperatures 200,250 , and $300^{\circ} \mathrm{C}$ for one hour. The value of annealing temperatures is chosen quite low as compared to crystalline temperature to avoid any crystallization due to annealing. XRD of the specimens are taken before and after each thermal annealing to show amorphous nature of the prepared and annealed specimens. Microhardness of the specimens is measured using Vickers method. SEM and AFM also are taken to observe surface morphology of the prepared samples. It is found that for $\mathrm{x}=15$ and annealing time of $200^{\circ} \mathrm{C}$ the maximum hardness is obtained.

\section{Experimental Procedure}

$\mathrm{Al}$ and $\mathrm{Cu}$ are used in the form of powder. The required amount of $\mathrm{Al}$ and $\mathrm{Cu}$ in the form of powder is used to prepare initial samples. Then by evaporation method in vacuum of $10^{-5}$ torr is deposited on glass substrate. Prepared samples are annealed in vacuum of $10^{-3}$ torr at temperatures 200, 250 and $300^{\circ} \mathrm{C}$ for 1 hour. Structure is characterized using $\mathrm{X}$ ray diffraction $(\mathrm{XRD})$ with $\mathrm{Cu}-\mathrm{K}_{\mathrm{a}}$ radiation with wavelength $=1.5405$ angstrom. Microhardness measurements are done using Buehler microhardness tester, with diamond pyramid, load of 10 grams and pressing time of 15 seconds. More than 10 measurements are performed and their average is considered. Jeol SEM is used to observe surface morphology and AFM is used to observe surface roughness of the samples.

\section{Results and Discussions}

\subsection{XRD Study}

Figure 1 show the XRD patterns of all prepared specimens before and after thermal annealing. It clearly shows broad halos typical for an amorphous structure. Specimens with compositions $\mathrm{Al}_{90} \mathrm{Cu}_{10}$ and $\mathrm{Al}_{80} \mathrm{Cu}_{20}$ show some crystalline phases, but the specimen with composition $\mathrm{Al}_{85} \mathrm{Cu}_{15}$ seems to be quite amorphous in structure without presence of any crystalline phase.

\subsection{Microhardness Measurements}

Microhardness of the specimens is measured before and after thermal annealing. Figure 2 shows the obtained microhardness values as a function of annealing temperatures.

It is observed that there is some increase in hardness of the all specimens due to thermal annealing, which can be related to densification of specimens. It can be considered that increase in hardness due to annealing is highest for sample with composition $\mathrm{Al}_{85} \mathrm{Cu}_{15}$ annealed at $200^{\circ} \mathrm{C}$ which may be related to its amorphous structure. Thermal annealing of other specimens cannot make such amount of increase in the microhardness.

\subsection{SEM Study}

We have studied the sample with composition $\mathrm{Al}_{85} \mathrm{Cu}_{15}$ because of its good increase in amount of microhardness after thermal annealing. Figure 3 shows micrographs of specimen obtained by SEM.

It shows clearly that the inter-atomic distances are decreasing or, one can say that the density of the specimen is increases upon thermal annealing which is in good agreement with our earlier result [11].

\subsection{AFM Results}

Figure 4 shows the surface roughness of the specimen by using AFM.

It shows that upon annealing the surface of the specimen becomes smoother due to structural relaxation occurred in the specimen after annealing. This phenomenon which arises due to low temperature thermal annealing can increase the density of the specimens and increase its hardness.

\section{Conclusion}

The effects of thermal annealing on prepared amorphous samples with composition $\mathrm{Al}_{100-\mathrm{x}} \mathrm{Cu}_{\mathrm{x}}$ were studied using XRD, microhardness tester, SEM and AFM. It is observed that sample with composition $\mathrm{Al}_{85} \mathrm{Cu}_{15}$ can give 


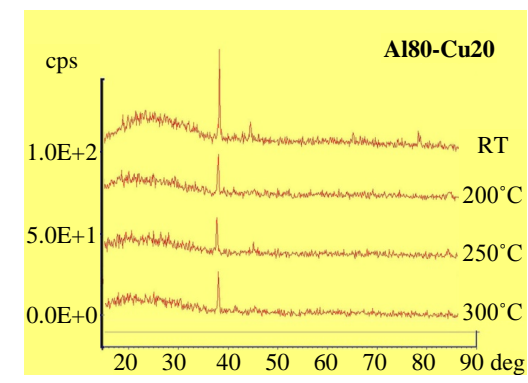

(a)

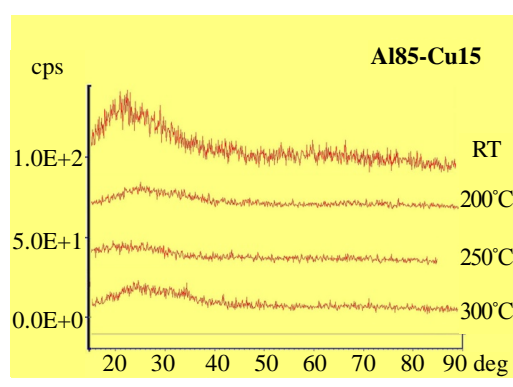

(b)

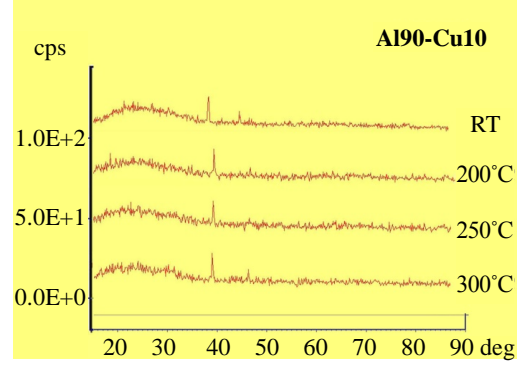

(c)

Figure 1. XRD patterns of samples before and after thermal annealing for different alloy compositions a: $\left(\mathrm{Al}_{80} \mathrm{Cu}_{20}\right)$, b: $\left(\mathrm{Al}_{85} \mathrm{Cu}_{15}\right)$, c: $\left(\mathrm{Al}_{90} \mathrm{Cu}_{10}\right)$.

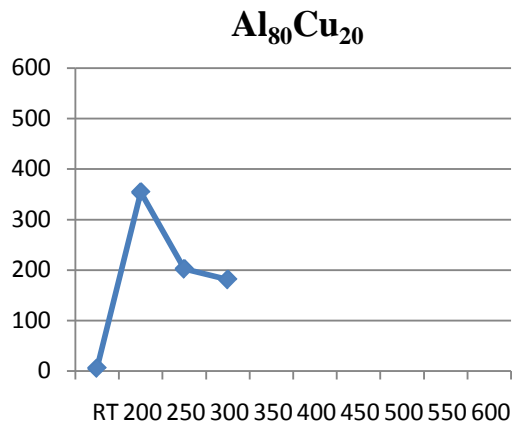

(a)

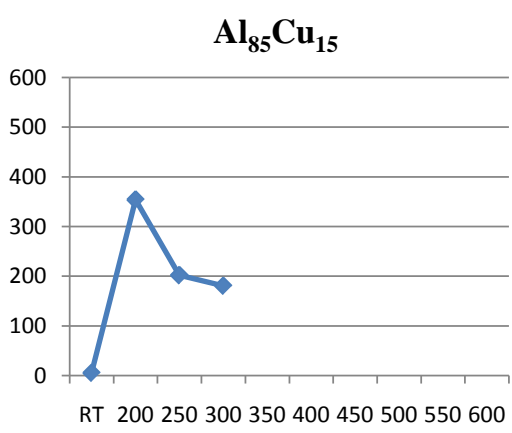

(b)

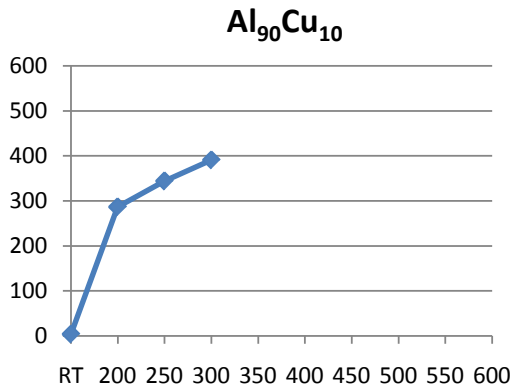

(c)

Figure 2. Microhardnes of the samples as a function of annealing temperatures for different alloy compositions, a: $\left(\mathrm{Al}_{80} \mathrm{Cu}_{20}\right)$, b: $\left(\mathrm{Al}_{85} \mathrm{Cu}_{15}\right)$ and c: $\left(\mathrm{Al}_{90} \mathrm{Cu}_{10}\right)$.

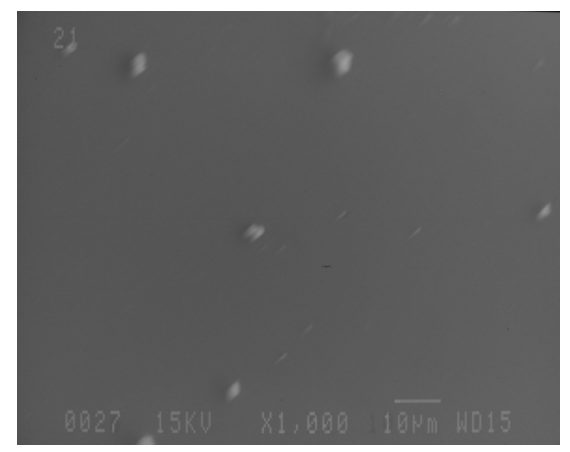

(a)

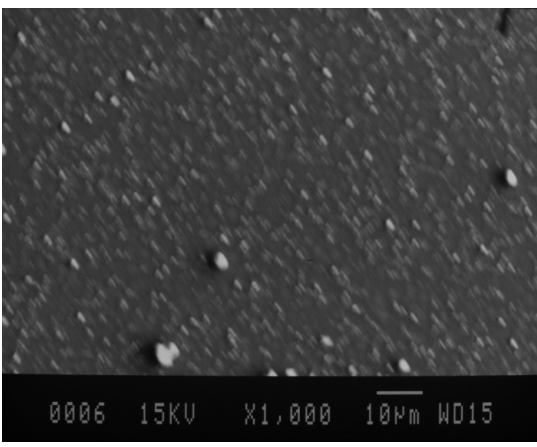

(c)

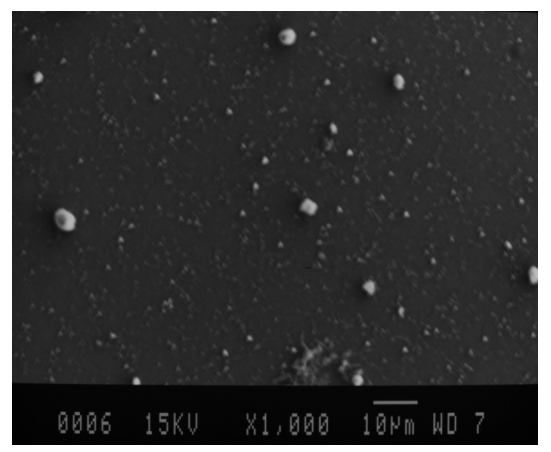

(b)

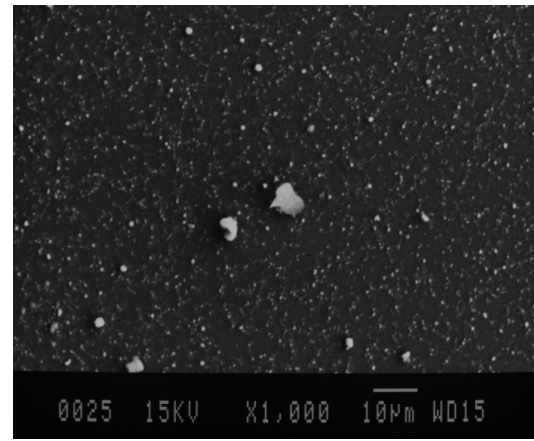

(d)

Figure 3. SEM micrographs of the sample $\mathrm{Al}_{85} \mathrm{Cu}_{15}$ before (a) and after thermal annealing b (200), c (250) and d $\left(300^{\circ} \mathrm{C}\right)$. 


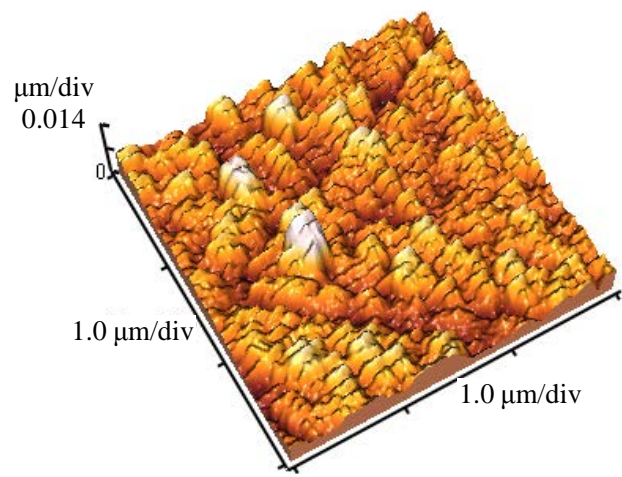

(a)

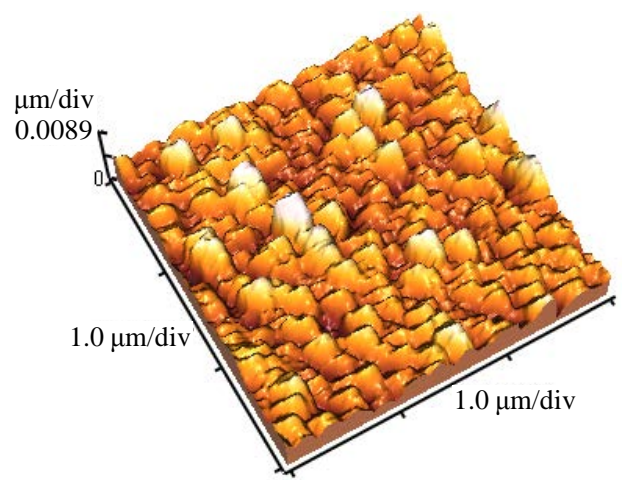

(c)

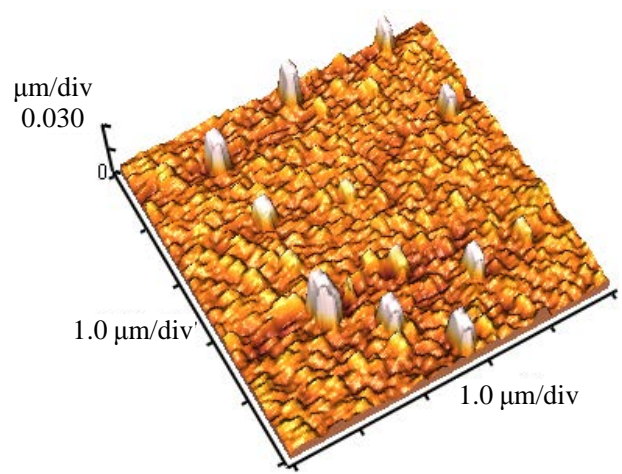

(b)

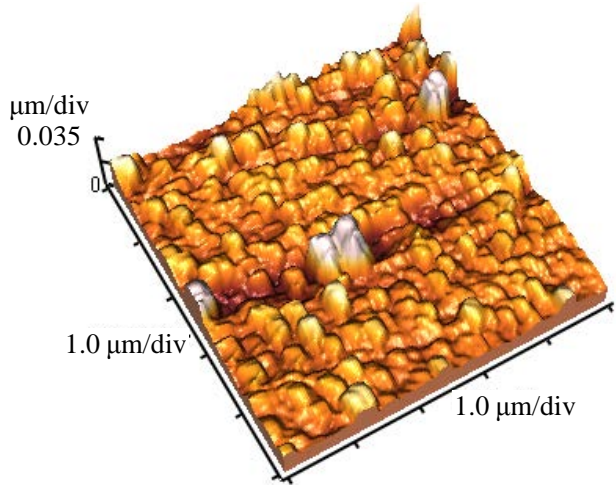

(d)

Figure 4. AFM of the sample $\mathrm{Al}_{85} \mathrm{Cu}_{15}$ before (a) and after thermal annealing b (200), c (250) and d $\left(300^{\circ} \mathrm{C}\right)$.

the best amorphous structure. Thermal annealing at temperature $200 \mathrm{C}$ for one hour can make maximum increase in microhardness of the specimen. And thermal annealing at selected temperatures can relax the specimen and densify it without occurrence of crystallization, hence better ductility can be achieved.

\section{References}

[1] Jiang, W.H. and Atzmon, M. (2006) Mechanically-Assisted Nanocrystallization and Defects in Amourphous Alloys, Scripta Materialia, 54, 333-336. http://dx.doi.org/10.1016/j.scriptamat.2005.09.052

[2] Wang, X.F., Wu, X.Q., Lin, J.G. and Ma, M. (2007) The Influence of Heat Treatment on the Corrosion Behaviour of As-Spun Amorphous Al88Ni6La6 Alloy in 0.01 M NaCl Solution. Materials Letters, 61, 1715-1717. http://dx.doi.org/10.1016/j.matlet.2006.07.186

[3] Wu, X.Q. and Xie, C.Q. (2008) Influence of Crystallization on Corrosion Resistance of $\mathrm{Al}_{86} \mathrm{Ni}_{6} \mathrm{La}_{6} \mathrm{Cu}_{2} \mathrm{Amorphous} \mathrm{Al}$ loy. Journal of Rare Earths, 26, 745-748. http://dx.doi.org/10.1016/S1002-0721(08)60175-1

[4] Tan, C.-G., Jiang, W.-J., Wu, X.-Q., Wang, X.-F. and Lin, J.-G. (2007) Effect of Crystallization on Corrosion Resistance of Cu22.5Ti30Zr11.5Ni6 Bulk Amorphous Alloy. Transactions of Nonferrous Metals Society of China, 17, 751754.

[5] Jiang, W.H., Pinkerton, F.E. and Atzmon, M. (2003) Deformation-Induced Nanocrystallization in an Al-Based Amorphous Alloy at a Subambient Temperature. Scripta Materialia, 48, 1195-1200. http://dx.doi.org/10.1016/S1359-6462(02)00568-7

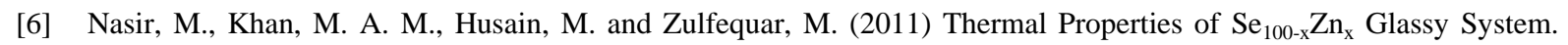
Materials Sciences and Application, 2, 289-298. http://dx.doi.org/10.4236/msa.2011.25038

[7] Kamruzzaman, M., Abu Sayem Karal, M., Saha, D.K. and Khan, F.A. (2012) Crystallization, Transport and Magnetic Properties of the Amorphous $\left(\mathrm{Fe}_{1-\mathrm{x}} \mathrm{Mn}_{\mathrm{x}}\right)_{75} \mathrm{P}_{15} \mathrm{C}_{10}$ Alloys. Journal of Crystallization Process and Technology, 2, 105110.

[8] Gogebakan, M. and Okumus, M. (2009) Structure and Crystallization Kinetics of Amorphous Al-Ni-Si Alloy. Materi- 
als Sience-Poland, 37, 79-87.

[9] Munoz-Morris, M.A. and Morris, D.G. (2010) Severe Plastic Deformation Processing of Al-Cu-Li Alloy for Enhancing Strength While Maintaining Ductility. Scripta Materialia, 63, 304-307. http://dx.doi.org/10.1016/j.scriptamat.2010.04.022

[10] Gao, M.C., et al. (2008) Development of fcc-Al Nanocrystals in Al-Ni-Gd Metallic Glasses during Continuous Heating DSC Scan. Materials Science and Engineering A, 485, 532-543. http://dx.doi.org/10.1016/j.msea.2007.08.009

[11] Habibi, S. and Soudmand, M. (2004) Study of Structural Relaxation in Alloys of Metallic Glasses. Surface and Interface Analysis, 36, 929-930. http://dx.doi.org/10.1002/sia.1802 